This is the pre-peer-reviewed version of the following article: "Santos, R.M, Van Gerven, T. (2011). Process Intensification Routes for Mineral Carbonation. Greenhouse Gases. Science and Technology, 1(4), 287-293.", which has been published in final form at http://dx.doi.org/10.1002/ghg.36.

\title{
PROCESS INTENSIFICATION ROUTES FOR MINERAL CARBONATION*
}

Rafael M. Santos and Tom Van Gerven, Katholieke Universiteit Leuven, Leuven, Belgium

Correspondence to: Tom Van Gerven, Katholieke Universiteit Leuven, Department of Chemical Engineering, Willem de Croylaan 46, B-3001, Heverlee, Belgium. E-mail: Thomas.VanGerven@cit.kuleuven.be

Abstract: Mineral carbonation is a realistic route for capture and storage of carbon dioxide. The principal advantages of this approach are the chemical stability and storage safety of mineral carbonates, the opportunities for process integration available, and the potential for conversion of low-value materials into useful products. In this work the valorisation of alkaline waste materials from thermal processes by mineral carbonation utilizing intensified and integrated mineral carbonation routes is explored. Process intensification is the chemical engineering of the $21^{\text {st }}$ century, and aims at providing the paradigm-shifting techniques that will revolutionize the industry. The combination of process intensification and process integration strategies has the potential to produce economically feasible and industrially acceptable carbonation technologies that can soon be implemented at large-scale, several examples of which are already proven at the laboratory scale and are herein discussed.

Keywords: mineral carbonation; process intensification; process integration; sustainability; ultrasound; waste valorisation

\footnotetext{
* This paper was in part presented at the Third International Conference on Accelerated Carbonation for
} Environmental and Materials Engineering (ACEME10), Turku, Finland, November 29 - December 12010. 


\section{INTRODUCTION}

To overcome the many inefficiencies that current technologies face and the feasibility barriers that hinder the applicability of new technologies, process intensification promises to be a key facet of engineering development for years to come. While the exact definition of process intensification varies, Stankiewicz and Moulijn ${ }^{1}$ have put it simply as "any chemical engineering development that leads to a substantially smaller, cleaner, and more energy efficient technology". Process intensification also means thinking in an integrated manner, seeking to bring together fundamental aspects of process engineering technology and finding the most optimum balance between them. In the last decade process intensification has grown from a loose terminology to a real engineering science. It is now a mature field, and is already being applied in the most challenging and important technological needs of our time (mitigation of greenhouse gases coming to mind). Herein, intensification routes for mineral carbonation are explored.

Mineral carbonation, as the name suggests, involves the transformation or capture of carbon dioxide in a mineral form. The principal aim and advantage of this approach is the chemical stability and storage safety of mineral carbonates, the opportunities for process integration presented by the technology, and the potential for valorisation of otherwise low-value resources (virgin or waste) into useful products. The main barriers to its deployment in industry, apart from the lack of legislative mandates in place, are one or more of: high energy intensity, low reaction conversion, slow reaction kinetics, complexities of the production chain, process adaptability, and competition for attention with alternative carbon capture technologies. The principal example of the latter is geological sequestration, by means of underground storage in geological formations such as depleted oil and gas fields, saline and basalt formations, and coal seams. It should be noted, however, that mineral carbonation by no means intends to replace the need for geo-sequestration, given the lack of sufficient mineral resources, especially suitable waste by-products, to capture the quantities of $\mathrm{CO}_{2}$ emitted from industrial sources. It is rather a complementary option, ideal for locations lacking easy access to suitable geological storage sites, or where process integration 
renders mineral carbonation more economically viable, or where mineral carbonation can contribute to industrial waste stabilization and valorisation.

A number of process challenges limit the successful translation of the theoretical process to industrial scale applications. At the particle level, the three rate limiting steps are: (i) leaching of cations; (ii) solvation and hydration of $\mathrm{CO}_{2}$; and (iii) diffusion to reaction zone (carbonated shell / depleted matrix). At the reactor level, three more limiting barriers are identified: (a) slow kinetics; (b) energy cost (heating/milling); and (c) mass of material (transport/handling). Numerous parameters are investigated to improve the various routes of mineral carbonation. These include: time, temperature, pressure, $\mathrm{CO}_{2}$ concentration, $\mathrm{pH}$, liquid-to-solid ratio, leaching agents, particle size, particle crystallinity, particle surface area and agitation. Still, published results over the last 20 years continue to lack the paradigm-shift needed to take mineral carbonation from the laboratory to the field ${ }^{2}$. An engineering catalyst (process intensification) is needed.

The drive to develop carbon capture technologies is centered on the perceived contribution of carbon dioxide emission to global warming due to the enhancement of the well-accepted greenhouse effect. Kaya ${ }^{3}$ has developed an expression that summarizes the factors that lead to anthropogenic $\mathrm{CO}_{2}$ emissions, called the Kaya Identity and expressed as:

$$
C O_{2}^{\Uparrow}=P O P \times \frac{G D P}{P O P} \times \frac{B T U}{G D P} \times \frac{C O_{2}^{\Uparrow}}{B T U}-C O_{2}^{\Downarrow}
$$

In order to reduce $\mathrm{CO}_{2}$ emissions, one or more of the multipliers on the right-hand-side must be reduced, or the last term must increase. Reducing the population $(P O P)$ or the standard of living $(G D P / P O P)$ is unlikely to be considered; on the contrary, these continue to increase as a result of the growth of developing nations. Hence it is necessary to address ${ }^{4}$ : (i) energy intensity (BTU/GDP; by efficient use of energy); (ii) carbon intensity $\left(\mathrm{CO}_{2}{ }^{\Uparrow} / B T U\right.$; by switching to non-fossil fuels such as hydrogen and renewable energy); and (iii) carbon capture $\left(\mathrm{CO}_{2}{ }^{\Downarrow}\right.$; by development of technologies to capture and sequester more $\mathrm{CO}_{2}$ ). Process intensification can aid in all three approaches, and in particular (iii) is explored in this work. 


\section{BASICS OF PI'S}

Van Gerven and Stankiewicz ${ }^{5}$ have categorized Process Intensification $\left(\pi_{1}\right)$ strategies in four fundamental domains (Figure 1: structure, energy, synergy and time), which may take shape of novel equipments and/or processes, and are applied to realize one or more of four objectives (Figure 1: i, ii, iii, iv). Each of these objectives can be readily related to the challenges of mineral carbonation. For example, incinerator bottom ashes are commonly aged (i.e. slowly carbonated) in open-air heaps for months to reduce $\mathrm{pH}$ and heavy metal leaching, typically with low success, before being landfilled. Not all material is equally exposed to the atmosphere, in fact only the topmost layer does. Simply moving the heaps occasionally or not immediately placing another layer of fresh bottom ash on top of aging ash can help homogenize the treatment and give the particles more equal experience (point ii).

Sustainable use of solid residues and carbon dioxide, the two largest and most important waste products from thermal processes, is an urgent issue both for the industry involved and society as a whole, considering the financial and environmental repercussions of their production. The K.U. Leuven's Knowledge Platform on Sustainable Materialisation of Residues from Thermal Processes into Products (SMaRT-Pro ${ }^{2}$ ) focuses on two types of waste-to-product valorisation: production of a carbon sink and valorised (construction) materials, by applying a Process Integration $\left(\pi_{2}\right)$ approach to mineral carbonation (Figure 2). The Platform focuses on the challenging aim of valorising solid materials and carbon dioxide by intensified processes with clear prospects on the economic and legislative feasibility, ecological benefits and societal relevance.

An optimised carbon sink should sequester a maximum amount of carbon dioxide without decreasing reaction rate over time. The questions of how much and how fast carbon dioxide can be sequestered by alkaline materials (e.g. slag or fly ash), and what are the limiting conditions for process rate and yield, are investigated. Strategies are developed to overcome current process barriers by comparison and optimization of different carbonation strategies, including hot-stage (during material production) and cold-stage (post-production) processes. Localized energy is also 
used for enhanced diffusion or for abrasion of the particles to obtain new reaction surfaces. For carbonated products, attention is given to the requirements of construction materials with a view to produce building materials in a sustainable way. Possible applications of these new raw materials are: 1) materials replacing natural aggregates in mortar and concrete, in ground stabilization and foundations of roads, in production of building blocks; 2) components that can be integrated in blended cements or binders in general; 3) possible non-structural materials such as thermal insulation material and materials for water barriers, both contributing to the reduction of energy consumption.

The combined application of process intensification $\left(\pi_{1}\right)$ and process integration $\left(\pi_{2}\right)$ is envisioned to provide the technological leap $\left(\pi^{2}\right)$ needed to make mineral carbonation industrially feasible, and moreover desirable.

\section{CASE STUDIES}

\subsection{Ultrasound Assisted Mineral Carbonation}

Process intensification encompasses a broad range of engineering technologies. Some of the leading areas of development make use of the following technological domains: photocatalysis, magnetic fields, ultrasound, microwaves, and microfluidics. The use of ultrasound in chemical processes, also termed sonochemistry, applies sound waves in the range of 16 to $100 \mathrm{kHz}$, based on the premise that as frequency is lowered, the power delivered increases. Power is delivered to a solution by inducing cavitation, that is, the formation of small cavities or microbubbles that grow and collapse rapidly. Cavitation generates turbulence/circulation, which enhances mass and heat transfer, both by improving convection mechanisms and by thinning diffusion-limiting boundary layers. The collapsing microbubbles produce high local temperature and pressure and high shear forces. These effects cause solid surface erosion, leading to the removal of passivating layers or to the eventual breakage of particles.

Several works are reported on the use of ultrasound for particle size reduction such as in

Lu et al. ${ }^{6}$ (silica particles), and Isopescu et al. ${ }^{7}$ (calcium carbonate). Rao et al. ${ }^{8}$ reported 
enhancement of carbonation of fluidized bed combustion ash by use of an ultrasound horn, where conversion extent was increased by threefold due to enhanced access of $\mathrm{CO}_{2}$ to the unreacted lime particle core, originally surrounded by a calcium sulphate shell. López-Periago et al. ${ }^{9}$ used a sonic bath to increase carbonation conversion of calcium hydroxide (from 65 to $89 \%$ over 1 hour) using supercritical $\mathrm{CO}_{2}\left(13 \mathrm{MPa}\right.$ at $\left.40{ }^{\circ} \mathrm{C}\right)$ Moreover, during precipitation of calcium carbonate from supersaturated aqueous solution, Kojima et al. ${ }^{10}$ observed the promotion of the vaterite polymorph over calcite under horn sonication (20 and $40 \mathrm{kHz}$, at room temperature) and the formation of smaller $(2 \mu \mathrm{m}$ compared to $20 \mu \mathrm{m})$ particles of calcium carbonate. Zhou et al. ${ }^{11}$ found pure aragonite polymorph to form from $\mathrm{Ca}\left(\mathrm{HCO}_{3}\right)_{2}$ solution at $70{ }^{\circ} \mathrm{C}$ with an ultrasound intensity of 58 $99 \mathrm{~W}$ at $20 \mathrm{kHz}$. The high temperatures and pressures, suitable for aragonite formation, caused by the ultrasound-induced cavitations were attributed to the result.

Ultrasound has been investigated by François ${ }^{12}$ (SMaRT-Pro $^{2}$ ) as a way to promote particle breakage during slurry carbonation, and to remove the carbonated shell or depleted matrix layers that surround the unreacted particle core, thus reducing diffusion limitations and exposing unreacted material to the aqueous phase. Sonication (Hielscher UP200S, $24 \mathrm{kHz}, 200 \mathrm{~W}$ ) was shown to increase the conversion (94\% vs. $86 \%$ over 25 minutes) and the process kinetics $(0.65$ vs. $0.59 \mathrm{~g}$ $\mathrm{CaCO}_{3} / \mathrm{min}$ ) of calcium hydroxide carbonation, compared to mechanical stirring. Furthermore, particle size reduction of calcium hydroxide and carbonate powders is significantly greater than of steel slag particles (Table 1). This is likely a result of lower hardness, confirming the premise that sonication can clear the surface of unreacted slag from the rate-limiting coverage of a carbonated shell.

Ceulemans $^{13}$ (SMaRT-Pro $^{2}$ ) used ultrasound together with magnesium chloride (as a pseudocatalyst) to induce the sonochemical formation of aragonite by carbonation of calcium hydroxide. The combined use of these two intensifying approaches permitted pure aragonite formation at $24{ }^{\circ} \mathrm{C}$, substantially lower temperature and higher purity than published in literature. ${ }^{11,14}$ The aragonite crystals formed under sonication also exhibited unique crystal morphology (rugby-ball 
shape) and reduced particle size. This novel material may have interesting applicability in industry as filler or pigment, as aragonite presents some improved physical and mechanical properties: improved tensile strength, impact strength, glass temperature and decomposition temperature in polymer application; improved brightness, opacity, strength and printability in paper coating application. $^{15}$

\subsection{Intensified Carbonation of Stainless Steel Slag}

A sustainable solution for the reuse of Argon Oxygen Decarbonisation (AOD) slag, generated in the stainless steel refining step, and Continuous Casting (CC) slag, produced during stainless steel casting, is still to be found. AOD slag exhibits a peculiar disintegration upon cooling due to the phase transformation of $\beta$-dicalcium silicate to the more stable, but less dense, $\gamma$-dicalcium silicate causing detrimental expansion forces in the material. The slag turns into a fine powder that causes severe dust issues during handling and storage in the steelworks; furthermore the slag in this form cannot be readily re-utilized or valorised, and often must be landfilled. One commonly used solution to avoid this problem is the incorporation of a small amount of doping agent (e.g. $\left.\mathrm{B}^{3+}\right)$ in the crystal structure, which stabilizes the $\beta$-phase, and produces a monolith product that has limited industrial application without further processing (e.g. crushing and milling). The boron addition also results in added processing cost and introduces environmental concerns regarding boron leaching. Furthermore, this methodology is not applied to CC slag due to process complexities, and the slag is disposed of in powder form by landfilling. More sustainable solutions leading to more useful products are desired.

One option, applying the principles of process intensification and integration, is to take advantage of the disintegration of AOD slag into a fine powder and apply it in an on-site mineral carbonation process using $\mathrm{CO}_{2}$-containing flue gases. The increased surface area should lead to increase carbonation reaction rates and conversion, resulting in considerable $\mathrm{CO}_{2}$ capture capacity (in the order of 0.5 tonne $\mathrm{CO}_{2}$ per tonne slag) and improved chemical properties ( $\mathrm{pH}$ and leaching). Baciocchi et al. ${ }^{16}$ studied the wet carbonation route of boron-free AOD slag (powder), and found 
maximum $\mathrm{CO}_{2}$ uptake after 8 hours at $50{ }^{\circ} \mathrm{C}, 10$ bar $\mathrm{CO}_{2}$ and 0.4 liquid-to-solid (L/S) ratio. The differential $\mathrm{CO}_{2}$ uptake of the aged slag, determined by calcimetry, was about $15 \mathrm{wt} \%$, resulting in $30 \mathrm{wt} \%$ overall uptake.

Vandevelde $^{17}$ (SMaRT-Pro $^{2}$ ) studied both boron-free AOD and CC slags (fresh powders) in wet carbonation at very mild conditions. Comparison of carbonation at $30{ }^{\circ} \mathrm{C}$ and $50{ }^{\circ} \mathrm{C}, 0.1$ and 0.2 bar $\mathrm{CO}_{2}$, and $\mathrm{L} / \mathrm{S}$ varying from 0 to 0.5 , allowed for determination of the optimum process conditions: $30{ }^{\circ} \mathrm{C}, 0.2$ bar $\mathrm{CO}_{2}, \mathrm{~L} / \mathrm{S}=0.3$. At these conditions, over 6 days, the $\mathrm{CO}_{2}$ uptake of AOD and CC slags were $11 \mathrm{wt} \%$ and $15 \mathrm{wt} \%$ respectively, equivalent to $32 \%$ and $45 \%$ Ca-conversion respectively. Santos et al. ${ }^{18}$ (SMaRT-Pro ${ }^{2}$ ) accelerated the process by performing slurry carbonation in a stirred autoclave (Buchi Ecoclave). Over 6 hours, at $60{ }^{\circ} \mathrm{C}$ and 3 bar $\mathrm{CO}_{2}$, fresh $\mathrm{AOD}$ slag reaches $12 \mathrm{wt} \% \mathrm{CO}_{2}$ uptake (37\% Ca-conversion) and fresh $\mathrm{CC}$ slag attains $17 \mathrm{wt} \% \mathrm{CO}_{2}(52 \% \mathrm{Ca}$ conversion). After 24 hours, $\mathrm{CC}$ slag carbonation continues, reaching $21 \mathrm{wt} \% \mathrm{CO}_{2}(65 \% \mathrm{Ca}-$ conversion), likely aided by particle-particle abrasion in the stirred system (1000 rpm), which aids in removing the carbonate passivating layer. This slag as such has been confirmed to be good $\mathrm{CO}_{2}$ sink and to be susceptible to accelerated carbonation through application of $\pi^{2}$ strategies. Further efforts can still better optimize the process, but a market for the valorised products is yet to be identified.

\subsection{Intensified Carbonation of Carbon Steel Slag}

The traditional use of Basic Oxygen Furnace (BOF) steel slag as an aggregate in road construction has been restricted due to the slag's undesirable expansive nature, attributed to the short and long term hydration of free lime $(\mathrm{CaO})$ and magnesium oxide $(\mathrm{MgO})$ content, resulting in rapid deterioration of the roads. To date, four forms of treatment have been widely used to stabilize BOF slag: (i) weathering in slag pits to convert free lime into hydrated lime, which is slow and inefficient; (ii) steam hydration of the slag and (iii) additions of $\mathrm{SiO}_{2}$ and $\mathrm{O}_{2}$ (to keep the slag molten) to the slag pot, which are expensive; or (iv) control of slag cooling path to stabilize tricalcium silicate phase, which is unreliable. A more attractive valorisation option is to take 
advantage of the waste heat released during BOF slag cooling, which can be used to fuel carbonation at higher temperatures, where the reaction kinetics are more favourable and can stabilize the free lime quickly and with low cost. Mikhail and Turcotte ${ }^{19}$ have shown this to be feasible.

Ling $^{20}$ (SMaRT-Pro ${ }^{2}$ ) systematically studied hot-stage carbonation of BOF slag, crushed to particle size between 0.1 and $1.6 \mathrm{~mm}$. Thermodynamic description (FactSage) of the BOF slag shows that of the major mineral phases, both free lime $(\mathrm{CaO})$ and srebrodolskite $\left(\mathrm{Ca}_{2} \mathrm{Fe}_{2} \mathrm{O}_{5}\right)$ are susceptible to carbonation at up to $880{ }^{\circ} \mathrm{C}$ and $670{ }^{\circ} \mathrm{C}$ respectively, at 1 bar $\mathrm{CO}_{2}$. Optimum carbonation conditions were found to be around $600-700{ }^{\circ} \mathrm{C}$, with up to $7 \mathrm{wt} \% \mathrm{CO}_{2}$ uptake achieved in 6 hours for the finest fraction $(<0.5 \mathrm{~mm})$, compared to already $4 \mathrm{wt} \% \mathrm{CO}_{2}$ uptake in only 10 minutes carbonation. Larger particle sizes achieved less carbonation extent, but similar $\mathrm{pH}$ reduction (about 1 unit) and heavy metal leaching attenuation (especially $\mathrm{Ba}, \mathrm{Co}$ and $\mathrm{Ni}$ ). Vanadium leaching, known to be a problematic element of BOF slag, though presently not regulated in Belgium or Netherlands, increased after carbonation; a solution to this issue is yet to be found. Nonetheless, this hot-stage carbonation routes appears attractive for industrial implementation given the process simplicity (e.g. molten slag granulation combined with fluidized bed reactor), energy efficiency (no external energy supply needed) and in-situ produced waste materials reuse $\left(\mathrm{CO}_{2}\right.$ from flue gas and slag).

\section{CONCLUSIONS}

Matching the right alkaline materials with the right mineral carbonation processes is key to overcoming the barriers that prevent this technology from reaching the market; this is the essence of process intensification and integration $\left(\pi^{2}\right)$. Work at SMaRT-Pro ${ }^{2}$ has contributed to the field of mineral carbonation by identifying disintegrated AOD slag as being ideal for slurry carbonation, and BOF slag as being a prime candidate for hot-stage carbonation. In addition, ultrasound has been proven to be a useful tool for intensification of mineral carbonation processes, both as a means of accelerating reaction kinetics and enhancing conversion, and as a promoter of the aragonite 
http://dx.doi.org/10.1002/ghg.36

polymorph of calcium carbonate for production of unique precipitated crystals. Further optimization of these processes is still required, however with the proof-of-concept now elucidated, it is hoped that soon these technologies will be scaled up, either by academia or industry, or ideally by joint collaboration.

\section{ACKNOWLEDGEMENTS}

The K.U.Leuven Industrial Research Fund (IOF) is gratefully acknowledged for funding the Knowledge Platform SMaRT-Pro ${ }^{2}$ in which this work was performed. R.M.S is thankful for the PGS-D support from the Natural Sciences and Engineering Research Council of Canada (NSERC).

\section{REFERENCES}

1. Stankiewicz AI and Moulijn JA, Process Intensification: Transforming Chemical Engineering. Chem Eng Prog 96(1):22-34 (2000).

2. Zevenhoven R, Fagerlund $\mathrm{J}$ and Songok $\mathrm{JK}, \mathrm{CO}_{2}$ mineral sequestration: developments toward large-scale application. Greenhouse Gas Sci Technol 1(1):48-57 (2011).

3. Kaya Y, Impact of Carbon Dioxide Emissions on GNP Growth: Interpretation of Proposed Scenarios. Intergovernmental Panel on Climate Change, Response Strategies Working Group, Geneva (2009).

4. Olajire $\mathrm{AA}, \mathrm{CO}_{2}$ capture and separation technologies for end-of-pipe applications - $\mathrm{A}$ review. Energy 35(6):2610-2628 (2010).

5. Van Gerven T and Stankiewicz A, Structure, Energy, Synergy, Time - The Fundamentals of Process Intensification. Ind Eng Chem Res 48(5):2465-2474 (2009).

6. Lu Y, Riyanto N and Weavers LK, Sonolysis of synthetic sediment particles: particle characteristics affecting particle dissolution and size reduction. Ultrason Sonochem 9(4):181-188 (2002).

7. Isopescu R, Mocioi M, Mihai M, Mateescu C and Dabija G, Modification of precipitated calcium carbonate particle size distribution using ultrasound field. Rev Chim 58(2):246-250 (2007). 
8. Rao A, Anthony EJ, Jia L and Macchi A, Carbonation of FBC ash by sonochemical treatment. Fuel 86(16):2603-2615 (2007)

9. López-Periago AM, Pacciani R, García-González C, Vega LF and Domingo C, A breakthrough technique for the preparation of high-yield precipitated calcium carbonate. $J$ Supercrit Fluids 52(3):298-305 (2010).

10. Kojima Y, Yamaguchi K and Nishimiya N, Effect of amplitude and frequency of ultrasonic irradiation on morphological characteristics control of calcium carbonate. Ultrason Sonochem 17(3):617-620(2010).

11. Zhou GT, Yu JC, Wang XC and Zhang LZ, Sonochemical synthesis of aragonite-type calcium carbonate with different morphologies. New J Chem 28(8):1027-1031 (2004).

12. François D. Ultrasound assisted mineral carbonation [Master's thesis]. Leuven, Belgium: Katholieke Universiteit Leuven; 2010.

13. Ceulemans P. Improved synthesis of aragonite [Master's thesis]. Leuven, Belgium: Katholieke Universiteit Leuven; 2011.

14. Park WK, Ko S-J., Lee SW, Cho K-H, Ahn J-W and Han C, Effects of magnesium chloride and organic additives on the synthesis of aragonite precipitated calcium carbonate. $J$ Cryst Growth 310(10):2593-2601 (2008).

15. Hua Z, Shao M, Cai Q, Ding S, Zhong C, Wei X and Deng Y, Synthesis of needle-like aragonite from limestone in the presence of magnesium chloride. J Mater Process Technol 209(3):1607-1611 (2009).

16. Baciocchi R, Costa G, Di Bartolomeo E, Polettini A and Pomi R, Comparison of different process routes for stainless steel slag carbonation, Proceedings of the Third International Conference on Accelerated Carbonation for Environmental and Materials Engineering, (ACEME10), November 29-December 1, 2010. Turku, pp. 193-202 (2010).

17. Vandevelde E. Mineral Carbonation of Stainless Steel Slag [Master's thesis]. Leuven, Belgium: Katholieke Universiteit Leuven; 2010. 
18. Santos R, François D, Vandevelde E, Mertens G, Elsen J and Van Gerven T, Process intensification routes for mineral carbonation, Proceedings of the Third International Conference on Accelerated Carbonation for Environmental and Materials Engineering, (ACEME10), November 29-December 1, 2010. Turku, pp. 13-22 (2010).

19. Mikhail SA and Turcotte AM, Thermal behaviour of basic oxygen furnace waste slag, Thermochim Acta 263:87-94 (1995).

20. Ling D. Thermal stabilization of steelmaking slag through high temperature carbonation treatment [Master's thesis]. Leuven, Belgium: Katholieke Universiteit Leuven; 2011.

\section{List of Tables:}

Table 1. Particle size reduction by sonication, expressed as Sauter Mean Diameter.

\begin{tabular}{llll}
\hline Powder & $\begin{array}{l}\text { Original } \\
D[3,2](\mu \mathrm{m})\end{array}$ & $\begin{array}{l}\text { Sonicated } \\
\mathrm{D}[3,2](\mu \mathrm{m})\end{array}$ & Reduction (\%) \\
\hline $\mathrm{CaCO}_{3}<200 \mu \mathrm{m}$ & 5.6 & 4.8 & $-14 \%$ \\
$\mathrm{CaCO}_{3} 200-500 \mu \mathrm{m}$ & 25.7 & 6.4 & $-75 \%$ \\
$\mathrm{Ca}(\mathrm{OH})_{2}$ & 1.8 & 0.9 & $-51 \%$ \\
$\mathrm{CC} \mathrm{slag}<200 \mu \mathrm{m}$ & 2.6 & 2.5 & $-5 \%$ \\
\hline
\end{tabular}

\section{List of Figures:}




\section{Process Intensification $\left(\pi_{1}\right)$}

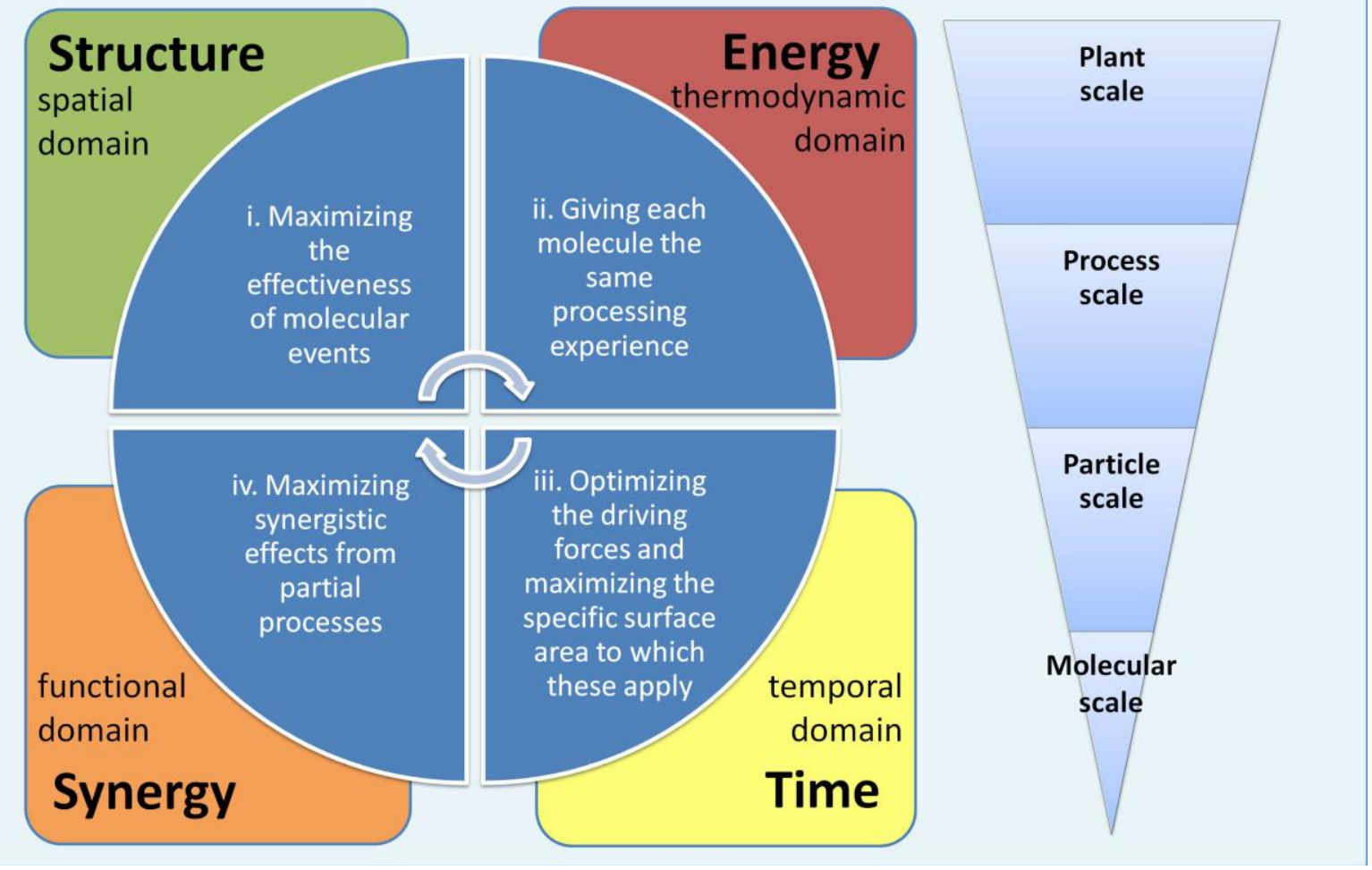

Figure 1. Principles of process intensification. 


\section{Process Integration $\left(\pi_{2}\right)$}

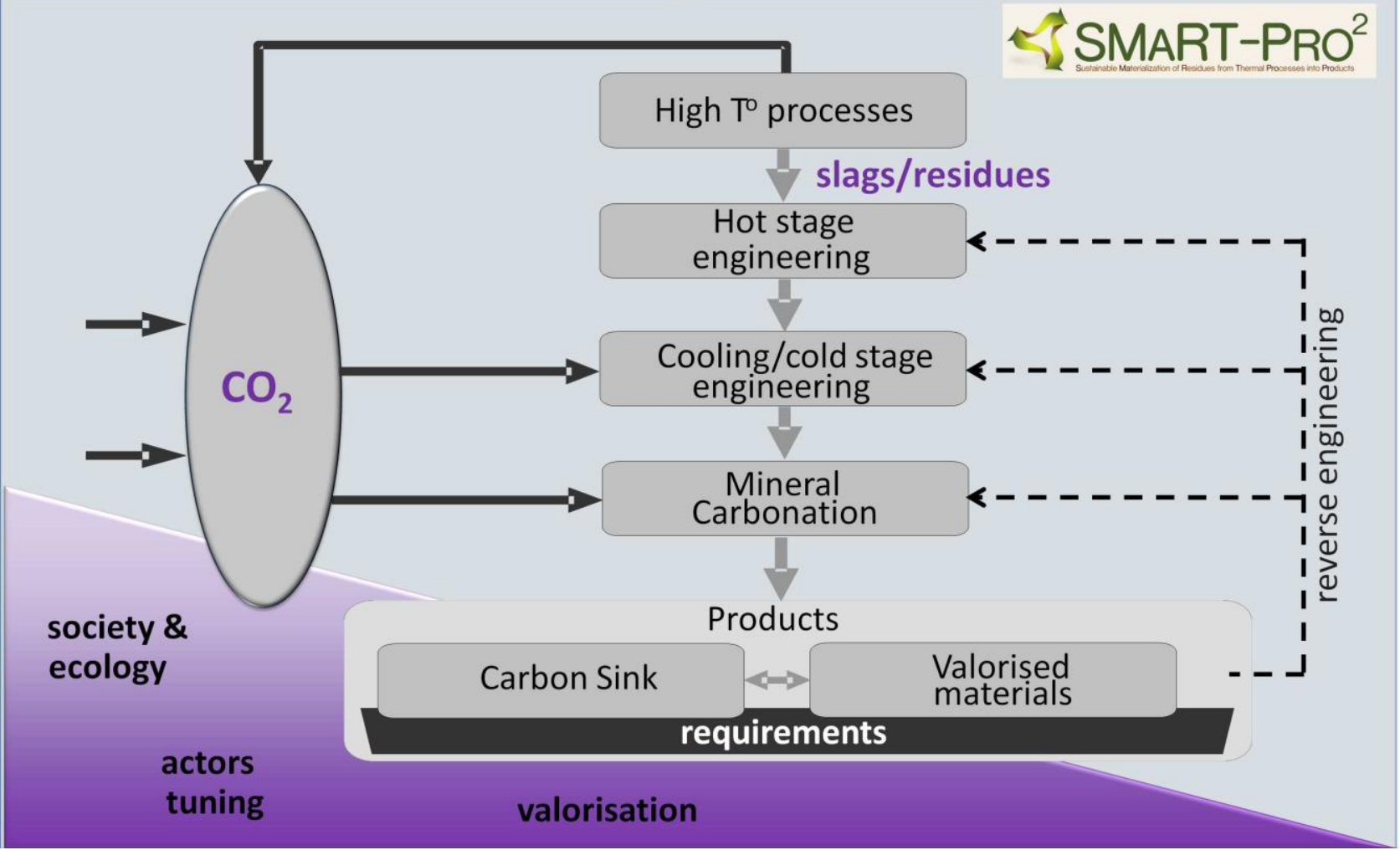

Figure 2. Integrated mineral carbonation of thermal residues; a framework of SMaRT-Pro ${ }^{2}$.

\section{Biographies:}

\section{Rafael Mattos dos Santos}

Rafael Mattos dos Santos is post-graduate researcher at the Katholieke Universiteit Leuven, Department of Chemical Engineering, and is a member of the SMaRT-Pro ${ }^{2}$ platform. He is working on sustainable materialization of residues from thermal processes into carbon sinks. He holds BASc and MASc (Chem Eng) degrees from the University of Toronto and is a registered Professional Engineer of Canada.

\section{Tom Van Gerven}


Tom Van Gerven is professor at the Department of Chemical Engineering of the Katholieke Universiteit Leuven, Belgium. He is coordinator of the SMaRT-Pro $^{2}$ platform, which brings together academia and industry on the issue of materials recycling. His scientific expertise covers process intensification and solid waste treatment, with special attention to mineral carbonation. He is the chairman of the Fourth International Conference on Accelerated Carbonation for Environmental and Materials Engineering (ACEME) to be organized in Leuven, Belgium. 